\title{
METODOLOGIAS DE ANÁLISE DE CADEIAS AGROINDUSTRIAIS: APLICAÇÃO PARA CITROS ${ }^{1}$
}

\author{
MARCOS FAVA NEVES ${ }^{2}$, FREDERICO FONSECA LOPES ${ }^{3}$, RICARDO MESSIAS ROSSI ${ }^{3}$, \\ PATRICIA APARECIDA DE OLIVEIRA MELO
}

\begin{abstract}
RESUMO - Este artigo teve como objetivo apresentar os principais resultados de um estudo de Sistemas Agroindustriais (SAG's) do PENSA e os principais resultados de sua aplicação à citricultura no Brasil. Este é um modelo utilizado para descrever diversas etapas metodológicas e quantificar em termos de faturamento os principais setores do agronegócio. A proposta visa a manter o objetivo que norteou o desenvolvimento do trabalho. No SAG dos citros foram identificadas as principais empresas privadas e instituições envolvidas, desde as indústrias de insumos, à citricultura, passando pela indústria processadora de citros, distribuição, até chegar ao consumidor final. As informações foram coletadas através de entrevistas, ponto central desta metodologia, buscando levantar o montante financeiro vendido pelas empresas no setor em estudo. Neste ponto, os dados obtidos são processados e inseridos na descrição do sistema (quantificação) e assim analisados. Foi gerado o desenho da cadeia de cítricos objetivando identificar possíveis ações coletivas, visando ao fortalecimento do setor.
\end{abstract}

Termos para indexação:citrus, SAG’s, agronegócio

\section{AGROINDUSTRY PRODUCTION CHAIN ANALYSIS METHODS AS APPLIED TO CITRICULTURE}

ABSTRACT - A study in which the Brazilian citriculture was evaluated by means of an analysis method developed by PENSA ( Study Programs of the Agroindustrial System Business ) is presented. This model is used to describe several methodological steps and to quantify the main agrobusiness sectors from a financial point of view. The most important private companies and institutions in some way linked to citrus production, starting with those producing the necessary inputs till those working in the processing and distributing of citrus products, were identified. The survey was conducted by means of interviews with the central objective of determining the total amount sold by the citrus companies. The whole citrus sector was maped out, aiming to locate where possible collective actions should be implemented viewing the strengthening of the sector.

Index terms: citrus, Agroindustrial Systems, agribusiness.

\section{INTRODUÇÃo}

Tão importante quanto a análise interna de um negócio está a análise externa, tanto do macroambiente (ambiente organizacional, institucional e tecnológico) quanto do ambiente imediato (fornecedores, concorrentes, distribuidores e consumidores). Esta realidade também é válida para empresas do agronegócio, justificando o crescente interesse em estudos relacionados à análise de Sistemas Agroindustriais (SAGs).A partir destes estudos, inúmeras contribuições podem ser fornecidas à sociedade, tais como: sugestões de políticas públicas, desenvolvimento de ferramentas de coordenação e governança, elaboração de ações coletivas que beneficiem todos os participantes de um sistema, entre outras. No entanto, o primeiro passo para o desenvolvimento de pesquisas de análise de cadeias é o conhecimento prévio do sistema a ser estudado. Assim, metodologias de caracterização de SAGs são imprescindíveis para o conhecimento e desenvolvimento das diferentes cadeias que constituem a economia de um país. Sabemos ainda que:

Cadeia de Suprimentos (Supply Chain) é um sistema cujas partes constituintes incluem os fornecedores de materiais, as fábricas, os serviços de distribuição e os clientes, alimentando "para frente" o fluxo de materiais e retornando "para trás" o fluxo de informações e recursos financeiros (Stevens apud Omta et al., 2001). É também uma rede de organizações que estão envolvidas diretamente, "corrente abaixo" ou "corrente acima", em diferentes processos ou atividades que agregam valor na elaboração de produtos e serviços, até chegar ao consumidor final (Christopher apud Omta et al., 2001).

Lazzarini et al. (2001) integram as análises de supply chain e network em um novo e amplo estudo denominado netchains. Para esses autores, a integração dessas duas abordagens permite a consideração de todos os tipos de interdependências organizacionais existentes em uma rede, assim como os diferentes mecanismos de coordenação (detalhamento do plano gerencial, padronização de processos e ajustes mútuos) e fontes de valor (otimização da produção e operações, redução dos custos de transação, diversidade e "co-especialização" de conhecimentos, entre outros).

Hardman et al. (2002) demonstraram a possibilidade de aumentar a competitividade das exportações da Cadeia da Maçã na África do Sul, por meio da cooperação entre produtores rurais, empacotadores e exportadores. A partir das idéias de commodity system approach (CSA) e de filière, é possível fundamentar discussões sobre o uso de ferramentas gerenciais para melhorar a eficiência de cadeias. Assim, os conceitos de Supply Chain Management (SCM) e o conjunto de idéias de formação de redes são novos aportes teóricos e empíricos à noção de Sistema Agroindustrial (Batalha \& Silva, 2001).

Segundo Morvan (1985), a análise de cadeias é um importante instrumento para descrever sistemas, definir o papel da tecnologia na estruturação dos sistemas produtivos, organizar estudos de integração, analisar políticas industriais e matrizes de insumo-produto, além de analisar estratégias de firmas e de associações.

O primeiro passo para caracterizar e analisar um sistema é definir seus objetivos, bem como seus limites, subsistemas componentes e contexto externo. Ao definir limites e hierarquias, estabelecem-se as interações de seus subsistemas componentes, mensuram-se suas entradas e saídas e respectivos desempenhos intermediários. Ao se analisar como um sistema opera, é necessário conhecer seus elementos, qualificando e quantificando (Castro, 2000).

As empresas situadas na estrutura do canal não são as únicas que influenciam no sistema. Também existem empresas denominadas "facilitadoras", que são organizações que, mesmo não fazendo parte do eixo central do canal, possuem funções importantes no mesmo. Conforme ressaltado por Rosembloon apud Neves (2000), são empresas transportadoras, de estocagem, de processamento de pedidos, de propaganda, de seguros, de pesquisa de mercado, agências financeiras, entre outras.

\footnotetext{
${ }^{1}$ (Trabalho 075/04). Recebido: 24/06/2004; Aceito para publicação: 10/12/2004. Este artigo apresenta os principais resultados de um projeto realizado pelo PENSA (Programa de Estudos dos Negócios do Sistema Agroindustrial) vinculado à Universidade de São Paulo e requisitado pelo Fundecitrus.

${ }^{2}$ Professor de Marketing e Estratégia da FEA/USP, Câmpus de Ribeirão Preto. Coordenador da Pesquisa (www.fearp.usp.br/fava), e-mail : mfaneves@ usp.br . Coordenador do Pensa em Ribeirão Preto.

${ }^{3}$ Professores da FEA/USP,Câmpus de Ribeirão Preto, e-mail: fflopes@usp.br e rrsossi@usp.br

${ }^{4}$ Bacharel em Administração de Empresas. UNIP/SP - e-mail :patriciaamelo@ zipmail.com.br
} 
O Sistema (Cadeia) Citrícola movimentou, em 2003, US\$3,23 bilhões, desconsiderando alguns setores, tais como atacado e varejo, ou seja, quase 10 bilhões de reais. O Sistema Agroindustrial Citrícola representa $1,87 \%$ da pauta total de exportações brasileiras, e 4,47\% das exportações brasileiras de produtos do agribusiness. Algo ao redor de US \$ 1,33 bilhão foi gerado ao Brasil em 2003 por este sistema em todas as suas exportações; $72 \%$ do valor destas exportações vêm do suco de laranja concentrado congelado (SLCC). O Estado de São Paulo concentra $79 \%$ da produção brasileira de laranja, em mais da metade de seus municípios, sendo responsável por 95\% das exportações de suco de laranja. O SLCC ocupou a segunda posição nas exportações paulistas em 2003, logo atrás de aviões; em pellets, o setor gerou em divisas US\$ 65 milhões para o Brasil em 2003, gerando 400 mil empregos diretos. Para cada US\$ 10 mil investidos na fruticultura, geram-se 5 empregos diretos e indiretos, em impostos federais (PIS/PASEP; COFINS; CPMF em cascata), e excluindo o setor de distribuição, o Sistema Agroindustrial citrícola recolheu US\$139,41 milhões em 2003, e o valor de fretes, dos insumos até o atacado, fica em torno de US\$103,5 milhões, e o de pedágio, em torno de US\$14,1 milhões.

O objetivo desse trabalho é propor um modelo de caracterização e quantificação de SAGs, baseado em informações de empresas privadas e associações atuantes no sistema em estudo, fornecer sugestões para a criação de organizações setoriais ,verticais representantes do sistema (compostas desde empresas de insumos até distribuidores finais). $\mathrm{O}$ resultado desse evento será uma lista de ações coletivas que poderá ser implementada tanto pela iniciativa privada quanto pelo governo. Associações verticais poderão ser criadas objetivando implementar as ações coletivas propostas.

\section{MATERIAL E MÉTODOS}

O método utilizado neste estudo foi elaborado a partir da união de conhecimentos acadêmicos e contribuições de executivos do mercado. Destaca-se que a sequiência metodológica foi sendo aprimorada nos últimos cinco anos com a aplicação em diferentes SAGs do agronegócio brasileiro.

A primeira etapa consiste na escolha do sistema que será o foco do estudo (por exemplo: SAG dos Citros). Após a priorização de um sistema, é elaborado um desenho preliminar, com base na experiência dos pesquisadores. Também é necessário delimitar quais segmentos serão estudados, mantendo o foco no eixo central do sistema (Figura 1)Sistema de Agribusiness e Transações Típicas).

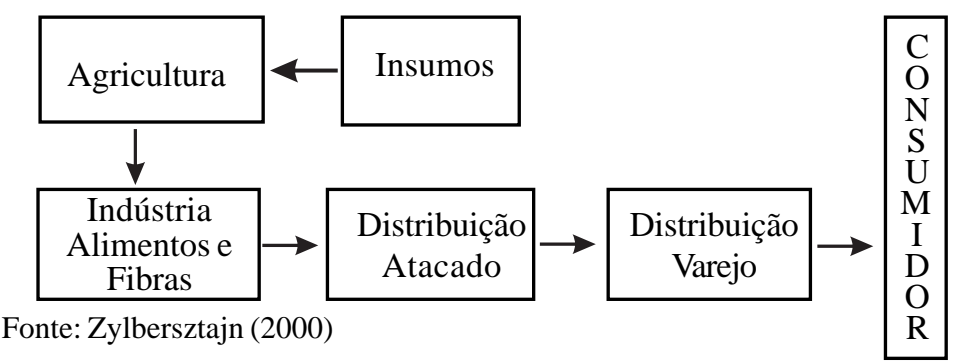

FIGURA 1 - Sistema de Agribusiness e Transações Típicas- Ambiente Organizacional: Associações, Informação, Pesquisa, Finanças, Cooperativas, Firmas e Ambiente Institucional: Cultura, Tradições, Educação, Costumes

Na segunda etapa, esse "desenho" será submetido a especialistas do setor, que deverão fazer os ajustes até que se obtenha uma estrutura simples e fiel à realidade.A terceira etapa consiste na pesquisa de dados secundários em diversas fontes, tais como: banco de dados, Internet, revistas especializadas, jornais, artigos acadêmicos e organizações especializadas (cooperativas, associações, institutos e outras). A quarta etapa é a coleta de dados primários por meio de entrevistas com representantes de diversas organizações que atuam no setor. Essas entrevistas são realizadas pessoalmente, por telefone ou por e-mail. As informações obtidas pelas entrevistas na quarta etapa da pesquisa são contrastadas e adicionadas aos conhecimentos levantados na revisão bibliográfica com intuito de se obter o desenho simplificado do SAG em estudo. Assim, as diferentes empresas pertencentes a cada nível do sistema são agrupadas e corretamente alocadas em uma estrutura de "caixas".

O resultado das primeiras etapas dessa metodologia é um desenho completo, porém estruturado de maneira simplificada (Figura 2) e conforme será mostrado nos casos do SAG da Laranja no Brasil. Com as informações coletadas nessas etapas, é possível o processo de quantificação de cada "caixa" da estrutura montada anteriormente. A informação básica para quantificar os diferentes elos do sistema é o faturamento de cada subsetor analisado, em determinado ano focal.

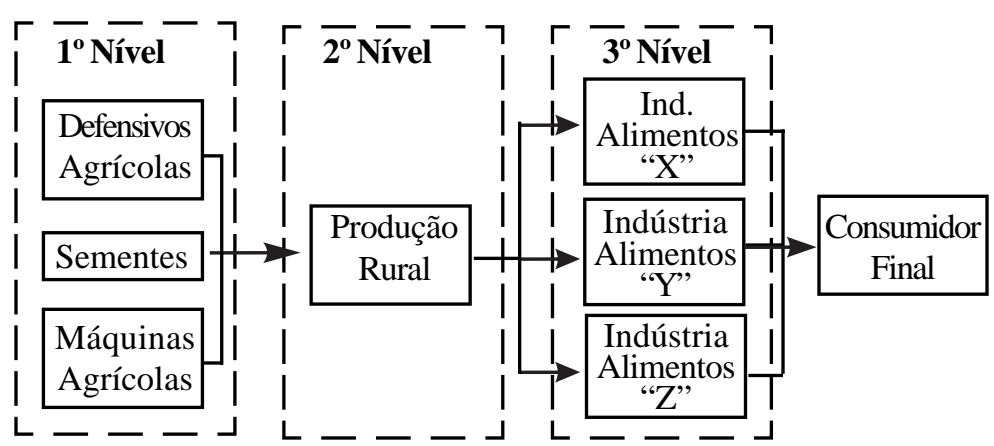

FIGURA 2 - Exemplo hipotético (simplificado) de Sistema Agroindustrial.

A quantificação, realizada na quinta etapa, consiste em determinar o faturamento (preço de venda) dos diversos subsetores da cadeia. Para isso, delimita-se o período da avaliação e a moeda a ser utilizada. Na sexta etapa, é realizado um Workshop para validação dos resultados, identificação de problemas de coordenação existentes no sistema e proposta de ações coletivas.

As seis etapas da seqüência metodológica proposta nesse artigo são resumidas no Tabela 1 .

O processo de estimação dos resultados está fortemente baseado em pesquisas de dados (data survey) e em entrevistas com especialistas no sistema. Entrevista em profundidade com especialistas é um método de estimação de demanda subjetivo, altamente recomendado quando o principal propósito da pesquisa é uma estimação a longo prazo. Esse é um método simples e com um grau de confiabilidade razoável, conforme comentado pela literatura sobre previsão de vendas (Churchill et al., 2000; Ingran \& Laforge, 1992; entre outros).

\section{RESULTADOS E DISCUSSÃO}

Apresentamos os principais resultados de um projeto realizado pelo PENSA (Programa de Estudos dos Negócios do Sistema Agroindustrial), vinculado à Universidade de São Paulo e requisitado pelo Fundecitrus (Fundo de defesa da Citricultura), uma entidade mantida por indústrias processadoras de suco e por produtores de laranja no Brasil. Apresentamos uma visão geral da importância econômica do Sistema Agroindustrial de Cítrus, segundo Neves et al. (2001).

As frutas cítricas são as mais produzidas no mundo, representando $22.5 \%$ de todas as frutas produzidas em 2000. O Brasil é o principal produtor de laranja do mundo, sendo também o maior produtor de suco do mundo ( $47 \%$ da produção total) e o maior exportador de SLCC (Suco de Laranja Concentrado Congelado), com $83 \%$ das exportações totais; a Citricultura representa quase $25 \%$ do valor da agricultura no Estado de São Paulo e $8 \%$ da produção agrícola brasileira; O Estado de São Paulo concentra $84 \%$ da produção brasileira de citros. Os pomares ocupam quase 36 mil fazendas, e o Estado de São Paulo produz aproximadamente $95 \%$ do total de suco (SLCC) exportado pelo Brasil. É um setor no qual o Brasil é muito 
TABELA 1 - Descrição das etapas da metodologia

\begin{tabular}{|c|c|}
\hline Etapa & Procedimento \\
\hline $\begin{array}{l}1^{\text {a: }} \text { Descrição do Sistema Agroindustrial em } \\
\text { estudo }\end{array}$ & $\begin{array}{l}\text { "Desenho" do sistema Agroindustrial por meio de "caixas" respeitando o fluxo dos produtos nos } \\
\text { canais de distribuição. }\end{array}$ \\
\hline $\begin{array}{l}2^{\text {a }} \text { : Submissão da descrição para executivos } \\
\text { do setor privado e outros especialistas, } \\
\text { visando a ajustes na estrutura. }\end{array}$ & $\begin{array}{l}\text { Com a primeira versão da descrição, algumas entrevistas em profundidade com executivos de empresas } \\
\text { atuantes no setor e outros especialistas (pesquisadores, lideranças setoriais, entre outros) devem ser } \\
\text { realizadas visando a ajustar a estrutura proposta. }\end{array}$ \\
\hline $\begin{array}{l}3^{\text {a }} \text { : Pesquisa por dados de vendas em } \\
\text { associações, instituições e publicações. }\end{array}$ & $\begin{array}{l}\text { Algumas associações privadas disponibilizam para seus membros dados sobre vendas, às vezes até } \\
\text { na Internet. Uma cuidadosa Revisão Bibliográfica também deve ser realizada em busca de dissertações/ } \\
\text { teses recentes, além de artigos em revistas/jornais de grande circulação ou acadêmicos. }\end{array}$ \\
\hline $4^{\text {a: }}$ Entrevistas com executivos de empresas. & $\begin{array}{l}\text { Este é o ponto central desta metodologia. São realizadas entrevistas com gerentes de vendas buscando } \\
\text { levantar o montante financeiro vendido pelas empresas no setor em estudo. } \\
\text { Por exemplo: A Basf vende defensivos agrícolas para todas as culturas. Nas entrevistas, o mercado da } \\
\text { Basf para a cultura do trigo seria discutido, questionando quanto a empresa vende para os triticultores } \\
\text { e qual o tamanho do mercado de trigo para a indústria de defensivos. Como somente os dados gerais } \\
\text { do tamanho do mercado serão publicados, as empresas não terão receio em colaborar. Ressalta-se que } \\
\text { os dados específicos de uma empresa serão preservados. } \\
\text { Também serão realizadas entrevistas com diretores de compra, visando a estimar o mercado a partir do } \\
\text { lado oposto de um elo da cadeia. } \\
\text { Por exemplo: Questionar aos moinhos de trigo quanto de açúcar eles compram e qual a sua participação } \\
\text { de mercado. Partindo deste ponto, é possível comparar os dados fornecidos pela indústria de açúcar } \\
\text { com os dados fornecidos pelos moinhos de trigo, observando a similaridade. }\end{array}$ \\
\hline $5^{\text {a }: \text { Quantificação }}$ & $\begin{array}{l}\text { Neste ponto, todos os dados obtidos são processados e inseridos na descrição do sistema, logo } \\
\text { abaixo do nome da indústria. Então, os dados são enviados para as empresas que colaboraram, que } \\
\text { analisarão os valores. As empresas enviam de volta os dados com seus comentários e contribuições. }\end{array}$ \\
\hline $6^{\text {a }: \text { Workshop }}$ & $\begin{array}{l}\text { Na fase final é realizado um workshop com uma hora para apresentação dos resultados e discussão } \\
\text { dos números. Depois disto, pequenos grupos de discussão são formados visando à elaboração de } \\
\text { ações coletivas que serão, na última parte do evento, apresentadas e resumidas em seção plenária. }\end{array}$ \\
\hline
\end{tabular}

competitivo, pois possui condições ideais do solo e temperatura, abundância de água para uso de irrigação, laranjas com qualidade superior, custo de produção e de colheita baixos, entre outros. Citros é o $13^{\circ}$ produto das exportações brasileiras, representando $2,6 \%$ de todos os produtos exportados e $9 \%$ dos produtos do agronegócio exportados pelo Brasil. Apenas em Pellets, o setor exportou USS 38,5 milhões em 2000 , menos de $1 \%$ das frutas são exportadas, mas foram responsáveis pela geração de divisas de USS 21 milhões em 1999 e de USS $15,3 \mathrm{em} 2000$. No total, essa cadeia trouxe algo em torno de USS 1,33 bilhão ao Brasil, considerando todas as suas exportações, em 1999. Aproximadamente $93 \%$ do valor das exportações vêm do suco de laranja concentrado e congelado (SLCC), cujo principal cliente é a União Européia, que importou 789 mil toneladas de SLCC em 2000, quase $70 \%$ das exportações brasileiras. O Nafta vem em segundo, com o $22 \%$, seguido por Japão e Coréia, com $10 \%$. Esses resultados demonstram os principais resultados que foram obtidos na pesquisa para o SAG de Citros, das vendas das empresas que fizeram parte destes setores em 1999.

No workshop, que foi apresentado para aproximadamente 50 agentes das principais empresas do SAG de Citros, o mercado interno foi apontado como uma alternativa para o escoamento da safra de cítricos, e foi o assunto principal da discussão do setor. Os consumidores no Brasil consomem em torno de 9 litros per capita / ano de sucos concentrado e congelado, enquanto são consumidos 45 litros per capita / ano pelos alemães e 22 litros per capita / ano pelos americanos. Os sucos têm apenas $4 \%$ do mercado brasileiro de bebida. Foi criado um comitê para desenvolver discussões relacionadas às ações com benefícios comuns, denominado "LaranjaBrasil" (www.laranjabrasil.com.br).

Parece que alguns dos membros da cadeia têm compreendido a importância em estabelecer as ações coletivas que beneficiarão a todos, e um relacionamento bom entre elas é muito importante também, atuando como parceiros, com o intuito de desenvolver ações integradas para melhorar o sistema inteiro.

\section{AAnálise econômica}

Empresas de insumos e o sistema agroindustrial citrícola As empresas de insumos faturaram, com citros, US\$ 362 milhões em 2003. A citricultura é responsável por 7,05\% das vendas de defensivos agrícolas do Brasil com um mercado de US\$ 141 milhões no ano de 2003, sendo o Brasil o terceiro mercado mundial em valor, para as empresas de defensivos. A citricultura é responsável pelo maior faturamento (2002) por hectare do setor - US\$141,95 / ha entre as principais grandes culturas, aproximadamente 3 vezes mais do que a segunda cultura (soja). O maior gasto $(\mathrm{kg} / \mathrm{ha})$ de ingrediente ativo (93\% do consumo de acaricidas no Brasil) é destinado à cultura de citros. Em 2003, o consumo de fertilizantes no Brasil para a cultura de citros foi de 370 mil toneladas (US\$ 75,8 milhões), representando $1,5 \%$ do total consumido no País. Apesar da queda em volume, o faturamento com as vendas para citros permaneceu relativamente estável (1998 - 2003), mostrando o aumento dos preços dos produtos e maior quantidade aplicada por área. Vale ressaltar que, junto com as culturas de café e cana-de-açúcar, a citricultura consome maior quantidade de fertilizante por hectare $(451 \mathrm{~kg} / \mathrm{ha})$. Na participação de $1,63 \%$ da frota mundial de tratores em 2003, foram comercializados aproximadamente 2.000 tratores apenas para citricultura, representando vendas de US $\$ 36,05$ milhões, $3,2 \%$ das vendas totais de tratores no Brasil. O mercado de implementos agrícolas, no ano de 2003, foi de US\$ 61,5 milhões para citros, com um crescimento de $15,3 \%$ entre os anos de 1999 e 2002. Ainda de 2002 para 2003 houve um aumento de $60 \%$ nas áreas de estufas para citros, com capacidade instalada de 23,4 milhões de mudas/ano. O mercado de mudas de citros em 2003 foi de US\$ 17 milhões; o consumo de corretivos agrícolas no Estado de São Paulo, em 2003, foi de 4 milhões de toneladas, sendo que somente a citricultura consumiu 0,8 milhão de toneladas $\left(20 \%\right.$ do mercado paulista, sendo o $2^{\circ}$ maior mercado), representando um faturamento de US\$15,44 milhões. O mercado de fertilizantes líquidos no Brasil é de 450.000 toneladas, onde a citricultura consome 60.000 toneladas/ano (US\$ 9,33 milhões), o $2^{\circ}$ 
maior mercado ( $13 \%$ do mercado). O fertilizante líquido para citros cresceu 133,25\% entre os anos 1999 e 2003, com vendas em torno de US\$ 4,22 milhões (2003), representando cerca de 5\% do mercado total brasileiro (US\$ 84,46 milhões) de fertilizantes foliares. Aárea irrigada em citros no Brasil é estimada em 84 mil ha, sendo 56 mil ha por sistema localizado e 28 mil por aspersão. Esses 84 mil ha irrigados, representaram 10,2\% da área total em 2003, enquanto em 1999 esse valor era apenas $1,5 \%$ da área total. A irrigação localizada no Brasil teve um crescimento de $64 \%$, enquanto a por aspersão teve um crescimento de 36\% de 1999 para 2003; citricultores compraram aproximadamente U\$20,15 milhões em irrigação no mesmo ano. (Figura 3)

\section{Citricultores e o sistema citrícola}

A produção agrícola faturou US\$ 809 milhões em 2003 tratando-se de um dos setores onde o Brasil é notadamente competitivo e produz aproximadamente $30 \%$ da laranja do mundo. A laranja representa $49 \%$ da produção brasileira de frutas (18.694 mil toneladas). A citricultura ocupa cerca de 820 mil ha no Brasil e 650 mil ha em São Paulo. Em 2002, no Estado de São Paulo, havia 211 milhões de plantas, sendo que $11 \%$ estão em formação e $89 \%$ em produção. Neste ano, a produção paulista foi de 280 milhões de caixas de 40,8 kg, com uma produtividade média de 1,74 caixa por planta; $50 \%$ das propriedades com laranja possuem uma área de 10 a 50 ha, sendo as principais regiões produtoras Barretos, Araraquara e Jaboticabal; 82,14\% da produção de laranja foi destinado ao processamento de suco; $17,26 \%$ para o mercado interno, e apenas $0,6 \%$ para exportação de fruta fresca. Citros emprega $2 \%$ da mão-deobra agrícola do Brasil e $11 \%$ do Estado de São Paulo. A laranja foi a cultura que apresenta maior renda bruta/ha com R\$ 4.652 em 2002, porém esta renda continua fortemente ameaçada pela morte súbita dos citros e pelo cancro-cítrico; A região Sudeste foi responsável por $77,27 \%$ da área colhida de laranja no Brasil, em 2002. Em São Paulo, os grandes produtores (mais de 150 mil plantas) representam menos de $1 \%$ do número total de propriedades e $45 \%$ da produção de laranjas, com uma produtividade de 2,46 caixas de $40,8 \mathrm{~kg} /$ planta, e produz 14.759 .067 toneladas com um rendimento de $25.150 \mathrm{~kg} / \mathrm{ha}$. É o terceiro produto em valor da produção, após a cana e a pecuária. Entre 1998 até o ano de 2003, houve um deslocamento da cultura das regionais agrícolas de Barretos, Jaboticabal e Limeira para as regionais de Araraquara, Botucatu e São João da Boa Vista. (Figura 3)

\section{Indústria e o sistema citrícola}

A indústria de suco de laranja concentrado e congelado (SLCC) consumiu 230 milhões de caixas de 40,8 kg em 2003, onde $82 \%$ da produção paulista de laranja destina-se ao processamento. O SLCC é o $17^{\circ}$ principal produto da pauta de exportação brasileira, sendo responsável também por $72 \%$ das exportações citrícolas e é o $2^{\circ}$ produto exportado pelo Estado de São Paulo com uma participação de $4,12 \%$ do total das exportações . A indústria citrícola consumiu $5,72 \%$ do total de bagaço de cana produzido no Estado de São Paulo em 2003, algo próximo a US\$ 16 milhões. Representou um mercado de US\$ 30 milhões em extratoras para o suco (2003). A produção brasileira de SLCC em 2002-2003 foi de 1.086 mil toneladas. Neste mesmo período, a exportação de SLCC foi de 1.136 mil toneladas (devido a estoques). A Bélgica já é a principal porta de entrada do suco brasileiro. O faturamento obtido com a comercialização desses sucos no Brasil, em 2003, foi US\$ 58,62 milhões. Entre as safras 1998-1999 e 20022003, o estoque final de SLCC caiu 65\%; em junho de 2003 o Brasil possuía um estoque final de SLCC de 119 mil toneladas. Os maiores importadores de SLCC do Brasil são Bélgica, EUA e Holanda. O faturamento obtido com a comercialização de sucos prontos (reconstituídos, pasteurizados e néctar) no mercado interno brasileiro, em 2003, foi US\$ 58,62 milhões (Figura 3).

\section{PACKING HOUSES e o sistema citrícola}

O brasileiro consome metade do que os italianos, alemães e espanhóis consomem de frutas/per capita. As exportações de laranja (fruta fresca) aumentaram, em valor, 64\% entre os anos de 2002 e 2003. Porém, menos que $1 \%$ de nossa produção é exportada, o principal destino das exportações brasileiras de laranja é a União Européia, e de tangerina o Oriente Médio. Embora aparentemente o mercado "formal" de suco fresco de laranja não esteja bem desenvolvido no País, ressalta-se que é enorme o consumo de suco fresco "caseiro", ou seja, obtido sem a utilização de extratoras específicas. Houve um crescimento de 14,87\% no número de Packing houses no Estado de São Paulo entre os anos de 2001 e 2004. A capacidade instalada é de $953 \mathrm{mil} / \mathrm{caixas} / \mathrm{dia}$, quase 4 vezes o que realmente foi movimentado nos Packing houses em 2003; houve uma redução de $40 \%$ no volume destinado ao mercado interno de $2003 \mathrm{em}$ relação a 2002. Estima-se que cerca de $90 \%$ das laranjas adquiridas pelo consumidor final seja transformada em suco caseiro (Figura 3 ).

As empresas de distribuição, o consumo e o sistema citrícola O CEAGESP tem uma participação de $8 \%$ do volume de laranja comercializado no mercado interno. Em 2003, foram comercializadas 709 milhões de embalagens p/ sucos; observa-se o crescimento da participação do pequeno e médio varejo na distribuição de suco. O consumo evoluiu de uma base de 66 milhões de litros em 1998 para 165 milhões de litros em 2002; com embalagens cartonadas, essas embalagens representam a maior parcela do consumo de sucos embalados; 58\% do mercado de bebidas não alcoólicas é de refrigerantes. O suco de laranja caseiro representa $15 \%$ e os industrializados, algo como $7 \%$. Os sucos prontos têm hoje apenas $2 \%$ do mercado de bebidas não alcoólicas brasileiro. No entanto, o suco de laranja caseiro detém $13 \%$ desse mesmo mercado. Do mercado (litros) total de sucos, néctares e refrescos (incluindo pó), $18 \%$ é do sabor laranja (2003). O suco de laranja perdeu participação no mercado para outros sucos de frutas, notadamente a manga, o pêssego e a uva. Das indústrias que produzem suco no País, $71 \%$ produzem suco de laranja; o mercado de sucos prontos para beber cresceu $30 \%$ entre 2002 e 2003 , em valores, e $7 \%$ em quantidade; no Brasil, a demanda vem crescendo à média de $40 \%$ ao ano nos últimos anos (Revista Distribuição, 2003), e em média, 65\% dos consumidores brasileiros têm no suco de laranja um dos principais sabores consumidos, seguido por: Pêssego, Maracujá e Manga.

Empresas prestadoras de serviços, fornecedoras de insumos intermediários e o sistema citrícola

O Sistema Agroindustrial Citrícola injeta US\$15,2 milhões nas empresas de transporte de suco a granel para o porto e também US\$ 4 milhões nas empresas que transportam o suco com tambores. Os transportadores de fruta das fazendas até a indústria e os packing houses faturam algo ao redor de US\$ 39,90 milhões por ano. Os transportadores de frutas dos packing houses para o mercado interno faturam algo ao redor de US\$19,02 milhões por ano. Só em óleo diesel (considerando o transporte de fruta e suco) o Sistema Citrícola é responsável por US\$ 66,37 milhões do faturamento do setor de combustíveis. As concessionárias que administram as rodovias, recebem da cadeia citrícola cerca de US\$ 14,12 milhões por ano. Segundo o Banco Central, em 2001, o crédito destinado à laranja para o custeio da lavoura e comercialização do produto atingiu $\mathrm{R} \$ 212,16$ milhões e R\$138,92 milhões, respectivamente. As empresas e pessoas envolvidas com mão-de-obra para colheita de citros faturaram ao redor de R \$ 76,02 milhões em 2003 (Figura 3). 


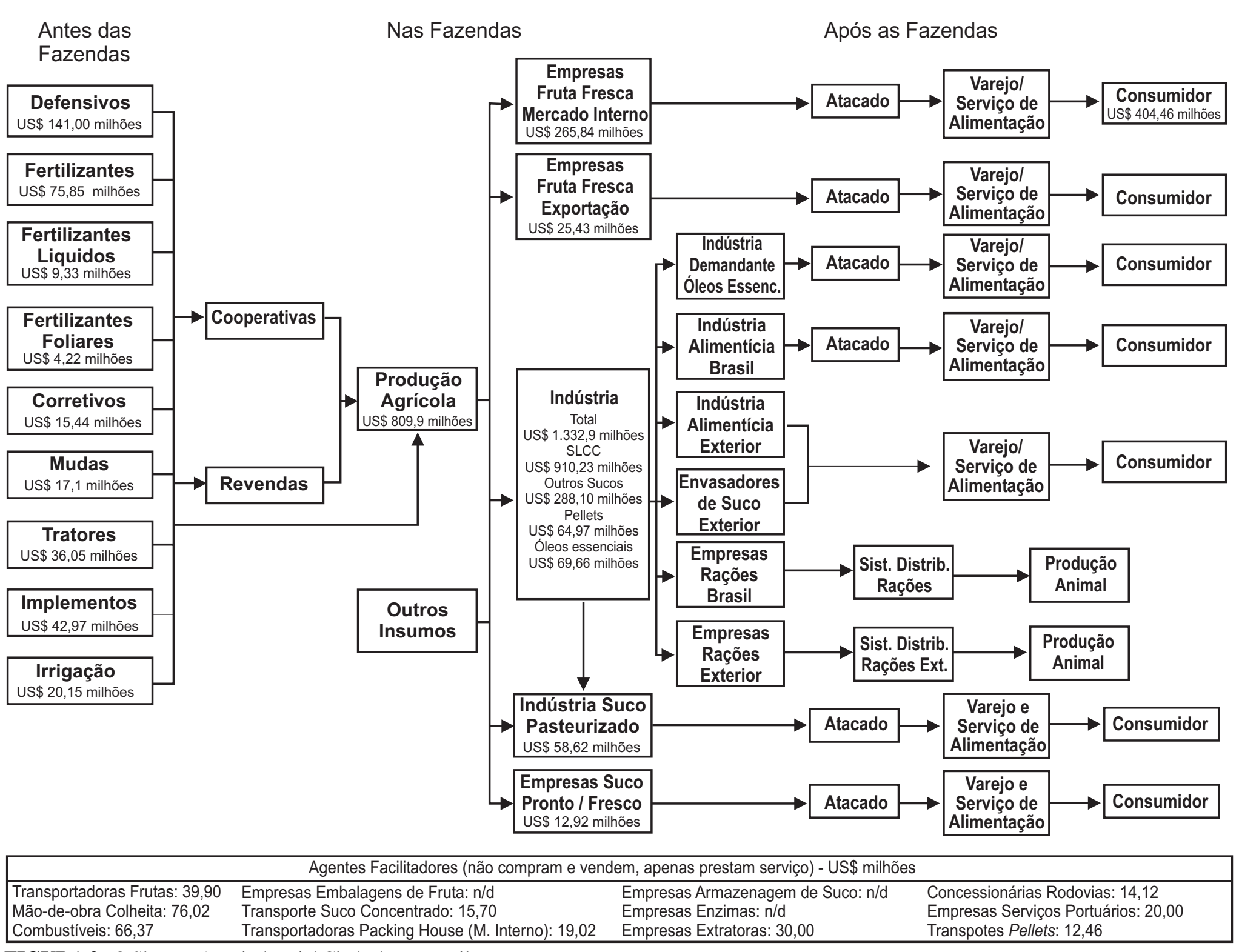

FIGURA 3 - O Sistema Agroindustrial Citrícola no Brasil

\section{CONCLUSÕES}

1. A metodologia é de aplicação relativamente simples e direta.

2. A coleta de informações não depende de fontes públicas de dados.

3. O desenho obtido permite a fácil visualização do posicionamento e relevância dos diferentes setores existentes em uma cadeia de valor.

4. A formação de grupos focais heterogêneos, para elaborar as listas de problemas e ações coletivas existentes em toda a cadeia, gera um ambiente de comprometimento entre os participantes do workshop. Este ambiente pode ser utilizado como ferramenta de integração da cadeia e implementação das ações coletivas que beneficiem todos os elos participantes.

5. Métodos alternativos de mensuração podem ser utilizados, tais como modelos de estimação baseados em análises estatísticas de demanda. Embora estes métodos possam oferecer maiores níveis de precisão, os acréscimos de custo e complexidade podem ser desinteressantes. O que realmente é necessário nesse tipo de estudo, são números gerais obtidos a partir de dados confiáveis, mostrando a importância das diferentes indústrias atuantes no sistema, incentivando a cooperação entre os diversos setores.

6. Os dados levantados para a quantificação do sistema foram obtidos por meio de fontes secundárias e entrevistas com especialistas selecionados, sem a preocupação de utilizar uma amostragem probabilística.
7. Para caracterizar o SAG de forma sistêmica, seria necessário analisar também os Ambientes Organizacional e Institucional, além das transações entre os setores. Tal análise não foi realizada neste estudo.

8. Os problemas de coordenação levantados e a "agenda" de trabalho elaborado são resultado das informações disponibilizadas por representantes de algumas empresas e associações. Assim, esses resultados refletem a opinião desses segmentos, podendo existir no sistema outros pontos de vista,proveniente de agentes que não participaram deste estudo.

9. Os Sistemas Agroindustriais são sistemas dinâmicos, portanto, os resultados aqui obtidos podem ser atualizados e melhorados em pesquisas futuras.

\section{AGRADECIMENTOS}

O modelo proposto tem limitações, e os autores ficariam agradecidos com contribuições recebidas pelos membros da ANPAD (Associação Nacional de Pós-Graduação e Pesquisa em Administração), no sentido de melhorar a metodologia.

\section{REFERÊNCIAS}

BATALHA, M. O.; SILVA, A. L. da. Gerenciamento de Sistemas Agroindustriais: Definições e Correntes Metodológicas. In: BATALHA, M. O. (Coord.). Gestão agroindustrial. 2. ed.São Paulo: Atlas,2001.v.1,p.23-63. 
CHURCHILL, A.G.; FORD, N.M.; WALKER O.C.; JOHNSTON M. W.; TANNER J. F. Sales force management.6.ed. Boston: Irwin McGrawHill2000.727p.,

HARDMAN, P. A.; DARROCH, M. A. G.; ORTMANN, G. F. Improving cooperation to make the South African fresh apple export value chain more competitive. Journal on Chain and Network Science, Wageningen, v. 2, n. 1, p. $61-72,2002$.

INGRAM, T.N.; LAFORGE, R.W. Sales Management: analysis and decision making. 2.ed. Orlando: HBJ, 1992.632p.

LAZZARINI, S. G.; CHADDAD, F. R.; COOK, M. L. Integrating supply chain and network analyses: The study of netchains. Journal on Chain and Network Science. Wageningen, v. 1, n. 1, p. 7-22, 2001.
MORVAN, Y. Filière de Production, in Fondaments d'economie industrielle, Economica, London, p. 199-231, 1985.

NEVES, M. F. Marketing no Agribusiness. In: ZYLBERSZTAJN, D.; NEVES, M. F. (Org.) Economia e gestão dos negócios agroalimentares. São Paulo: Pioneira, 2000.p. 109- 136.

NEVES, M. F; VAL, A. M.; MARINO, M. K. The Orange Network in Brazil. Fruit Processing, Schönborn,, v.11, n.12, p.486 - 490, 2001.

OMTA, O.; TRIENEKENS, J.; BEERS, G. The knowledge domain of chain and network science. Journal on Chain and Network Science, Wageningen, v. 1, n. 2, p. $77-85,2001$.

ZYLBERSZTAJN, D. Conceitos gerais, evolução e apresentação do sistema agroindustrial. In:ZYLBERSZTAJN, D; NEVES, M. F. (Org.) Economia e gestão dos negócios agroalimentares. São Paulo: Pioneira, 2000.p. $1-21$. 